\title{
Effect of Synthesis Conditions on Formation Pathways of Metal Organic Framework (MOF-5) Crystals
}

\author{
Colin McKinstry, ${ }^{\dagger,}$ Edmund J. Cussen, ${ }^{\ddagger}$ Ashleigh J. Fletcher, ${ }^{*}{ }^{\dagger}$ Siddharth V. Patwardhan, ${ }^{\dagger}$ \\ and Jan Sefcik ${ }^{\dagger}$ \\ ${ }^{\dagger}$ Department of Chemical and Process Engineering, University of Strathclyde, 75 Montrose Street, Glasgow, G1 1XJ, U. K. \\ ${ }^{\ddagger}$ WESTCHEM, Department of Pure and Applied Chemistry, University of Strathclyde, 295 Cathedral Street, Glasgow, G1 1XL, U. K. \\ Supporting Information
}

ABSTRACT: Metal Organic Frameworks (MOFs) represent a class of nanoporous crystalline materials with far reaching potential in gas storage, catalysis, and medical devices. We investigated the effects of synthesis process parameters on production of MOF-5 from terephthalic acid and zinc nitrate in diethylformamide. Under favorable synthesis conditions, we

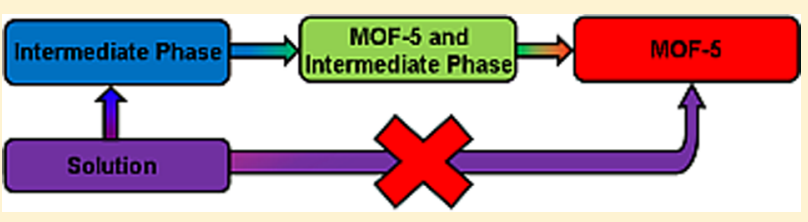
systematically mapped a solid formation diagram in terms of time and temperature for both stirred and unstirred conditions. The synthesis of MOF-5 has been previously reported as a straightforward reaction progressing from precursor compounds in solution directly to the final MOF-5 solid phase product. However, we show that the solid phase formation process is far more complex, invariably transferring through metastable intermediate crystalline phases before the final MOF-5 phase is reached, providing new insights into the formation pathways of MOFs. We also identify process parameters suitable for scale-up and continuous manufacturing of high purity MOF-5.

\section{INTRODUCTION}

Metal Organic Frameworks (MOFs), or coordination polymers, ${ }^{1}$ are of great interest due to several unique features: supramolecular design of MOFs allow a number of organic ligands, with two or more functional groups, to be linked to metal ion coordination centers giving myriad variations and tunable properties in synthesized structures. ${ }^{2}$ The scaffoldlike nature of the frameworks produces almost no inaccessible "dead" space within the structure, allowing gas storage applications to be taken further than would be possible by zeolites or activated carbon materials. ${ }^{3}$ Furthermore, potential for functionalizing MOF compounds, either during synthesis or postsynthesis gives rise to a variety of potential uses for MOFs, such as gas storage and separation, catalysis, and medical devices. $^{4}$

MOF-5, with composition $\mathrm{Zn}_{4} \mathrm{O}(\mathrm{BDC})_{3}$ (BDC = benzene dicarboxylate anion), discovered in 1999 by Yaghi et al., ${ }^{5}$ has been synthesized using a number of methodologies. Solvothermal methods are the most commonly applied, requiring very little specialist equipment compared to microwave, ${ }^{6}$ ultrasonic enhanced synthesis, ${ }^{7}$ synthesis using surfactants ${ }^{8}$ or via substrates, ${ }^{9}$ while maintaining a high degree of crystallinity, porosity, and high surface area. ${ }^{10}$

Previous literature on solvothermal synthesis of MOF-5 has encompassed a range of synthetic procedures. While previous reports are generally based on single step synthesis approaches, one paper ${ }^{18}$ suggests a two-step solvothermal synthesis route, with an aging step before initiation at increased temperature. Zinc precursors include a number of possible salts, such as nitrate, sulfate, acetate, oxide, chloride, and also zinc acetate, which already includes the $\mathrm{Zn}_{4} \mathrm{O}$ cation that must be formed in solution when the other salts are used. Within this range of options, however, Biemmi et al. ${ }^{11}$ report that zinc nitrate and zinc acetate produce MOF-5 in a pure phase, while zinc oxide precursor produces $\mathrm{MOF}-5$ with $\mathrm{ZnO}$ impurities clearly present. The zinc sulfate precursor produces a crystalline phase but not MOF-5, whereas zinc chloride produces only an amorphous phase(s) under conditions analyzed there. Therefore, given the low cost of using zinc nitrate, it is the most commonly used zinc salt utilized in the vast majority of the reported literature analyzed, with varying levels of hydration present. Hexahydrate and tetrahydrate represent the two most common zinc nitrate species used, with hexahydrate the more widely used. Other papers suggest using partially dehydrated zinc nitrate or do not define the level of hydration present in their salt. The water content is thought to affect both the rate of reaction and the final product, and so its effect needs to be considered.

Metal:ligand ratios of 3:1 are common in the literature, while some papers used a stoichiometric ratio of 4:3. Literature review suggests that, with few exceptions, one of these two procedures is used. The former is based on the production of 1\% MOF-5 solids and the latter 3\% solids. Increasing the solid concentration would allow MOF-5 to be formed using less solvent, leading to an increase in both environmental and economic viability. This allows for a reduction in energy costs and requires less solvent; the solvent issue is vital to economic viability of a MOF-5 synthetic system as diaprotic polar solvents, such as DEF and DMF, are relatively expensive and

Received: October 1, 2013

Published: October 22, 2013 
associated waste requires careful disposal. As $1 \%$ solids represents $1 \mathrm{~g} / 100 \mathrm{~mL}$ and $10 \%$ solids represent $10 \mathrm{~g} / 100$ $\mathrm{mL}$, an increase in \% solids can significantly reduce the amount of solvent used. Furthermore, DEF recycling is a nontrivial task due to its decomposition to form diethyl amine when heated in the presence of water. Diethyl amine, when present at sufficient concentration in the reaction solution, can cause formation of an alternative crystalline structure, ${ }^{12}$ hence, the efficient use of DEF is vital.

Solvothermal syntheses involve a wide range of conditions, and many procedures are relatively slow, typically lasting $20 \mathrm{~h}$ or more, ${ }^{13,14}$ at temperatures close to or above $100{ }^{\circ} \mathrm{C} .1^{15,16}$ Other reported synthetic procedures suggest that shorter durations, at higher temperatures, may lead to more efficient MOF-5 formation; Zhao et al. ${ }^{17}$ have produced MOF-5 in just $2 \mathrm{~h}$ at $130{ }^{\circ} \mathrm{C}$. Figure SIl of the Supporting Information shows a time-temperature map for solvothermal synthesis conditions obtained from literature (see the Supporting Information).

The crystallographic complexity of these structures has tended to require preparative methods that yield high-quality single crystals, typically via crystal growth along a concentration gradient. The classical model of crystal formation would suggest that these materials are formed by combination of reagents in solution, condensing to nucleate crystals, which then further grow. It has been previously proposed ${ }^{18}$ that the first solid phase formed in the system studied here is MOF-5, and the application of light scattering techniques ${ }^{18}$ to study the onset of solid state formation as a marker for final crystalline product formation relies on such a linear relationship.

Here, we show that, even in the case of a thermodynamically stable coordination polymer such as MOF-5, it cannot be assumed that the final product is formed by direct reaction in the solution phase. Instead, the product evolves from a complex series of reactions involving other metastable solid phases, crystallizing from solution, before undergoing subsequent transitions to MOF-5. In this paper, we report an investigation on the formation of initial solid phases along the solvothermal pathway in MOF-5 synthesis, starting from zinc nitrate and terephthalic acid in DEF, at temperatures between 110-140 ${ }^{\circ} \mathrm{C}$, in times up to $6 \mathrm{~h}$. Analysis of other experimental parameters, such as salt hydration, stirring, and reactant concentrations, allowed identification of process parameters suitable for scale-up and continuous manufacturing of high purity MOF-5.

\section{EXPERIMENTAL METHODS}

Zinc nitrate tetrahydrate, $0.157 \mathrm{~g}(0.6 \mathrm{mmol})$ (Emsure $\geq 98.5 \%)$, and terephthalic acid, $0.0333 \mathrm{~g}(0.2 \mathrm{mmol})$ (Alfa Aesar 98+\%), were dissolved in $5 \mathrm{~mL}$ (45 mmol) of $\mathrm{N}$ - $\mathrm{N}$-diethylformamide (DEF) (Alfa Aesar, 99\%) in $23 \mathrm{~mm}$ diameter flat bottomed glass vials. A $\mathrm{Zn}: \mathrm{BDC}: \mathrm{H}_{2} \mathrm{O}$ molar ratio of 3:1:12 was used, unless otherwise stated; hence, maximum theoretical yield of MOF- 5 was $1 \mathrm{~g} / 100 \mathrm{~mL}$ solution. Parallel samples were placed into a preheated oil bath and stirred with $5 \mathrm{~mm}$ PTFE magnetic stirrer bars. Vials were left in an oil bath for the designated experimental time, varied between $30 \mathrm{~min}$ and $6 \mathrm{~h}$ in increments of $30 \mathrm{~min}$ or $1 \mathrm{~h}$. After reaching the required experimental duration, vials were removed and the contents pipetted onto filter paper and air-dried. Experiments were carried out at 140, 130, 120, and $110^{\circ} \mathrm{C}$. The effect of stirring upon synthesis was analyzed by repeating the above synthesis without stirring the solutions.

In order to study the effect of zinc salt hydration on the reaction products, a hexahydrate salt was used for synthesis. Zinc nitrate hexahydrate (Alfa Aesar, 99\%), $0.178 \mathrm{~g}(0.6 \mathrm{mmol})$, and terephthalic acid, $0.0333 \mathrm{~g}(0.2 \mathrm{mmol})$, were dissolved in $5 \mathrm{~mL}(45 \mathrm{mmol})$ of $\mathrm{N}-\mathrm{N}$ diethylformamide. A $\mathrm{Zn}: \mathrm{BDC}: \mathrm{H}_{2} \mathrm{O}$ molar ratio of 3:1:18 was used; hence, maximum theoretical yield of MOF- 5 was $1 \mathrm{~g} / 100 \mathrm{~mL}$ solution. Solutions were stirred and heated as described previously. Solids began to precipitate after $30 \mathrm{~min}$.

The effect of the metal:ligand ratio was also investigated, using ratios of 3:1, 1.33:1, 1:1, and 0.67:1. The maximum theoretical MOF-5 yield was maintained at $1 \mathrm{~g} / 100 \mathrm{~mL}$. Additionally, the effect of increasing the solid content was investigated; a $\mathrm{Zn}: \mathrm{BDC}$ :water ratio of 3:1:12 was maintained. The following maximum theoretical MOF-5 yields were examined: $3,5,10,20$, and $30 \mathrm{~g} / 100 \mathrm{~mL}$. All reaction parameters were maintained as described above, except for the starting concentrations of zinc nitrate and terephthalic acid. The syntheses described above are referred to as single-step syntheses and were all performed in duplicate.

Analogously, with two-step syntheses, the solutions were preheated to $60{ }^{\circ} \mathrm{C}$ for 24,48 , and $72 \mathrm{~h}$. At this point, samples were removed for analysis and an identical sample used for initiation at $75^{\circ} \mathrm{C}$ for $1.5 \mathrm{~h}$. This allowed a comparison of the effect of aging on the system along with initiation temperature.

The prepared samples were characterized by powder X-ray ATR Diffraction (XRD), Fourier-Transform Infrared (FT-IR) spectroscopy, Thermal Gravimetric Analysis (TGA) and $\mathrm{N}_{2}$ adsorption/desorption. $\mathrm{XRD}$ results were collected using $\mathrm{Cu} \mathrm{K} \alpha(\lambda=1.54 \AA)$ radiation. Thermal Stability tests were performed using a Mettler Toledo TGA/ DSC. Approximately $10 \mathrm{mg}$ of sample was heated under $\mathrm{N}_{2}$ at $10{ }^{\circ} \mathrm{C} /$ $\mathrm{min}$. Nitrogen adsorption/desorption measurements were carried out on a Micromeritics ASAP 2420 at $-196{ }^{\circ} \mathrm{C}$; samples were degassed by heating to $200{ }^{\circ} \mathrm{C}$ for $10 \mathrm{~h}$ at $10 \mu \mathrm{m} \mathrm{Hg}$. Infrared spectra were recorded using an ABB Bomem MB 3000 Fourier Transform NearInfrared Spectrometer, with a resolution of $4 \mathrm{~cm}^{-1}$. The spectra obtained are the average of 64 interferograms per sample. Samples were analyzed as a fine powder using an attached horizontal Attenuated Total Reflectance (ATR) assembly.

\section{RESULTS AND DISCUSSION}

Effect of Salt Hydration. In order to investigate the potential impact of water concentration on the system, MOF-5 was synthesized using either tetrahydrate or hexahydrate of zinc nitrate. The addition of water to the standard solvothermal synthesis for MOF- 5 has been known to cause an alternative final product to be formed (MOF-69c), with Rosi et al. ${ }^{19}$ adding water with zinc nitrate hexahydrate to further increase the water content, which does not appear to be desirable. With the use of $130^{\circ} \mathrm{C}$ and $3 \mathrm{~h}$ as standard conditions, where we consistently observed synthesis of pure phase MOF- 5 using the tetrahydrate salt, MOF-5 was also formed when using the hexahydrate salt. In Figure 1, however, XRD results show that the MOF-5 produced using the hexahydrate salt has some small impurities present that were also formed, under identical conditions, using the tetrahydrate salt. Though a bulk phase of MOF-5 is formed, the results show some shouldering of Bragg peaks, and the presence of small low intensity Bragg peaks from intermediate phases still present within the bulk material.

Effect of Metal:Ligand Ratio. Variation of the metal/ ligand ratio $(\mathrm{M} / \mathrm{L})$ was studied over the range from 3 to 0.67 . All reaction systems were prepared so as to keep the final concentration of MOF-5 (at 100\% theoretical yield) identical. Samples with $\mathrm{M} / \mathrm{L} \geq 1.33$ produce MOF-5 on comparable timescales. For values below 1.33 (representing stoichiometry of the final product), the final product was a solid phase other than MOF-5; reducing the M/L ratio below 1.33 causes terephthalic acid to be in excess, which appears to prevent MOF-5 formation. MOF- 5 formed at M/L 1.33 shows superior crystallinity to MOF-5 formed with $\mathrm{M} / \mathrm{L} 3$, with narrower Bragg peaks (see Figure 2).

Effect of Time and Temperature. Despite the large body of scientific literature regarding characterization and analysis of 


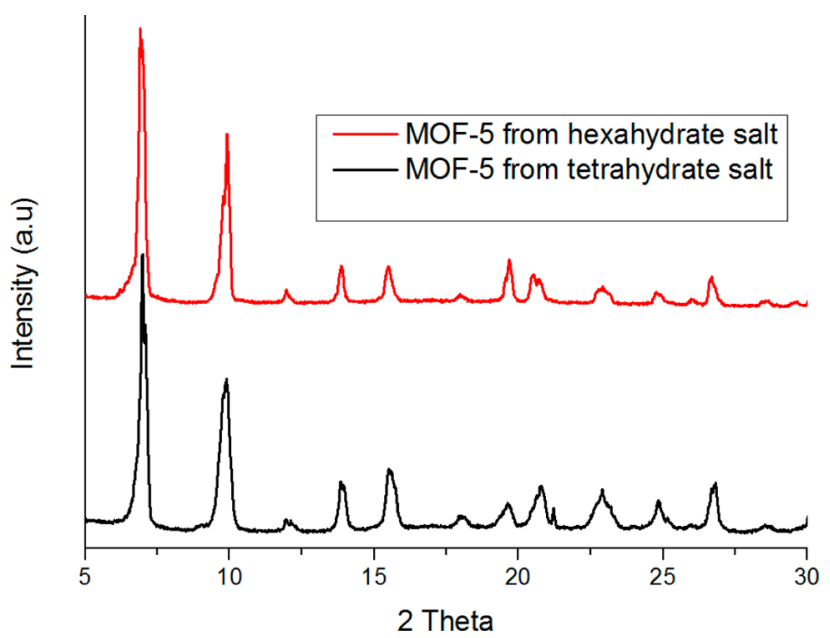

Figure 1. Comparison of the effect of precursor salts with different hydrations after heating to $130{ }^{\circ} \mathrm{C}$ for $3 \mathrm{~h}$. Tetrahydrate salt results in fewer impurities compared to the hexahydrate salt.

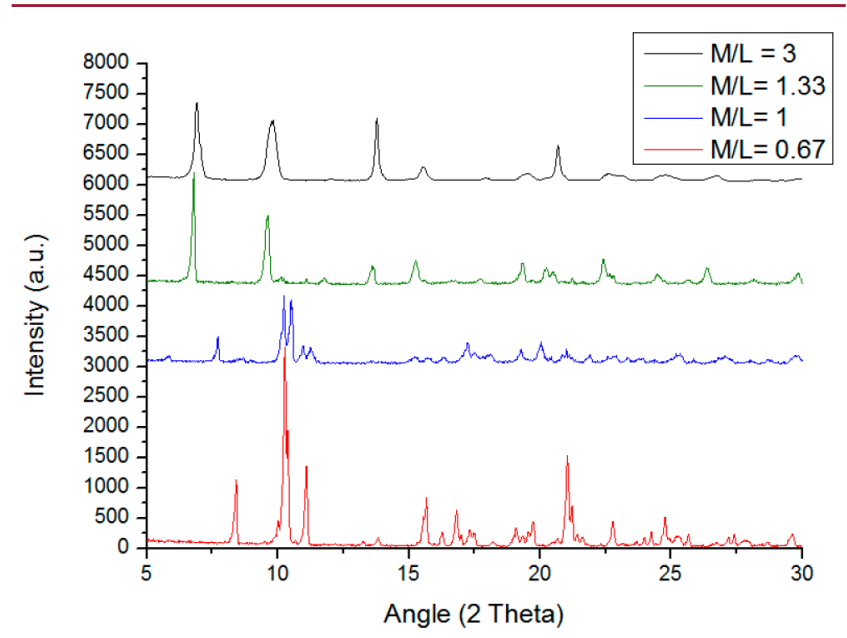

Figure 2. Comparison of the effect of altering the metal/ligand ratio. Samples were heated at $130{ }^{\circ} \mathrm{C}$ for $3 \mathrm{~h}$.

MOF-5 properties, only a papers have been published on the effects of specific synthesis conditions on MOF-5 formation, and no work has been published on mapping solid phase formation pathways in MOF-5 synthesis from reactant solutions. Detailed mapping of a time-temperature parameter space allowed new insights into the formation mechanisms of MOF-5.

At $140{ }^{\circ} \mathrm{C}$, under stirred conditions, the reaction mechanism was found to follow the simplest pathway among all conditions investigated, with an intermediate phase [identified as MOF$69 \mathrm{c}$ (desolv), see below] formed first before gradual conversion to MOF-5 at longer times. Reducing the synthesis temperature below $140{ }^{\circ} \mathrm{C}$ resulted in far more complex reaction pathways being formed with multiple intermediate solid phases present during the process. Due to the metastable nature of these transient, short-lived phases and the presence of multiple phases, their isolation and subsequent characterization was not possible.

Figure 3 shows XRD patterns of solid phases formed at 140 ${ }^{\circ} \mathrm{C}$ under stirring conditions. Longer heating times result in MOF-5 in a pure state, as confirmed by powder XRD, consistent with previous literature. ${ }^{5}$ Thermal stability of the final MOF-5 product was analyzed by TGA and showed

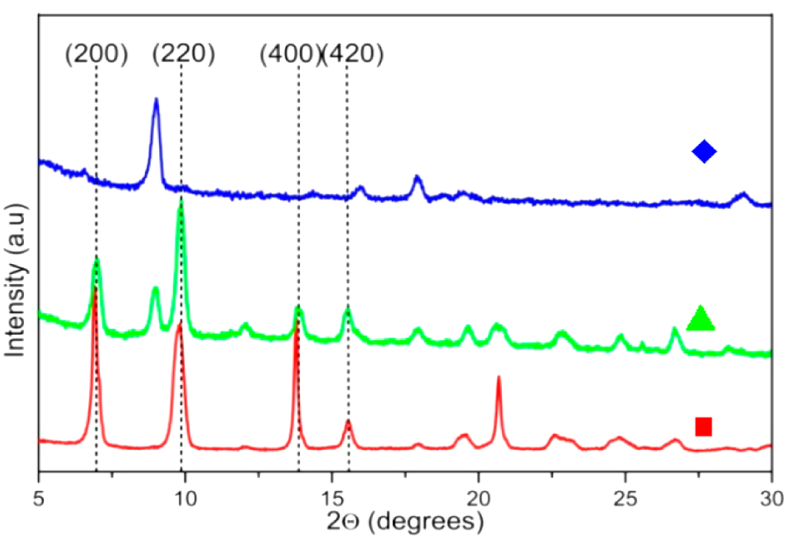

Figure 3. XRD results for single-step synthesis showing MOF$69 \mathrm{c}$ (desolv) (main peak at $8.9^{\circ}$ ) (blue $>$ ), MOF-5 + MOF69c(desolv) (green $\boldsymbol{\Lambda}$ ), and MOF-5 (red $\boldsymbol{\square})$.

thermal stability to $375{ }^{\circ} \mathrm{C}$ and mass loss in line with the breakdown of the unit cell and ligand loss from the structure (Figure SI3 of the Supporting Information).

The intermediate phase observed under these conditions is isostructural with phases described by Hausdorf et al. ${ }^{20}$ and Kaye et al. ${ }^{21}$ Hausdorf produced a phase denoted as MOF$69 \mathrm{c}$ (desolv) by reacting pure phase MOF-5 in DEF and water to produce MOF- $69 \mathrm{c}$, before heating under argon to produce the desolvated phase, composition $\mathrm{Zn}_{3}(\mathrm{OH})_{2}(\mathrm{DBC})_{2}$. Though this phase has been obtained by postsynthesis, as discussed above, it has never been shown before to be present as a solid precursor phase in the direct synthesis of MOF-5. MOF-5 is known to be sensitive to moisture present in air, with Kaye et al. $^{21}$ showing the breakdown of MOF-5 into MOF-69c, in moist air, over a $24 \mathrm{~h}$ period. MOF-69c was first synthesized by Rosi et al. ${ }^{19}$ by adding water to the MOF-5 synthesis route, producing a layered structure with low porosity. However, other researchers used different nomenclature for the same phase, with Hausdorf et al. ${ }^{20}$ using the term "MOF$69 \mathrm{c}$ (desolv)" to indicate that XRD results show the desolvated phase.

In our system, the reaction scheme for conversion between MOF-69c(desolv) and MOF-5 is as follows:

$$
\begin{aligned}
& 4 \mathrm{Zn}_{3}(\mathrm{OH})_{2}(\mathrm{BDC})_{2}+\mathrm{H}_{2} \mathrm{BDC} \leftrightarrow 3 \mathrm{Zn}_{4} \mathrm{O}(\mathrm{BDC})_{3}+5 \mathrm{H}_{2} \mathrm{O} \\
& \mathrm{MOF}-69 \mathrm{c}(\text { desolv })+\text { terephthalic acid } \leftrightarrow \mathrm{MOF}-5+\text { water }
\end{aligned}
$$

There is further evidence for this mechanism from FT-IR results, shown in Figure 4, which show an increase in intensity of peaks characteristic of the $\mathrm{Zn}$ :ligand framework located at 1650 and $1435 \mathrm{~cm}^{-1}$, coupled with a reduction in intensity of the $\mathrm{OH}$ peak located at $3000-3600 \mathrm{~cm}^{-1}$, for MOF-5 compared to MOF-69c(desolv). The peak at $1650 \mathrm{~cm}^{-1}$ represents a characteristic shift of the $\mathrm{O}-\mathrm{C}-\mathrm{O}$ of the deprotonated terephthalic acid, due to coordination with the zinc of $\mathrm{Zn}_{4} \mathrm{O}$ tetrahedra, from $1610 \mathrm{~cm}^{-1}$, indicative of uncoordinated terephthalic acid. ${ }^{13}$ The peak located at 1435 $\mathrm{cm}^{-1}$ also indicated the presence of deprotonated carboxylic acid bonded within the MOF-5 framework, ${ }^{14,22}$ reduced for MOF-69c(desolv). The presence of water, indicated by a broad peak at $\sim 3000-3600 \mathrm{~cm}^{-1}$ is greatly increased for MOF69c(desolv).

Figure 5 shows a map of solid state outcomes in the parameter space of time and temperature used in this study in order to give a wider overview of the complexity of MOF-5 


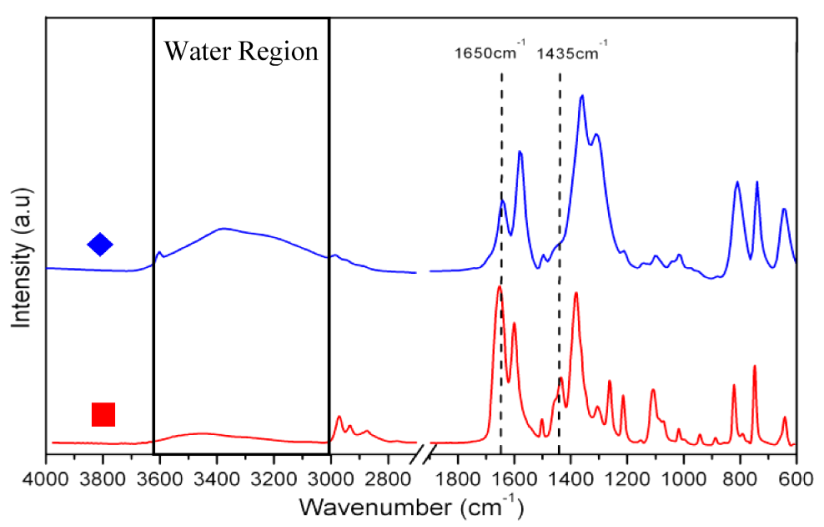

Figure 4. FT-IR for MOF-69c(desolv) (blue $\diamond$ ) and MOF-5 (red $\mathbf{\square})$. Series of peaks located at $2800-2900 \mathrm{~cm}^{-1}$ are indicative of the formic acid formed due to the breakdown of the DEF solvent.

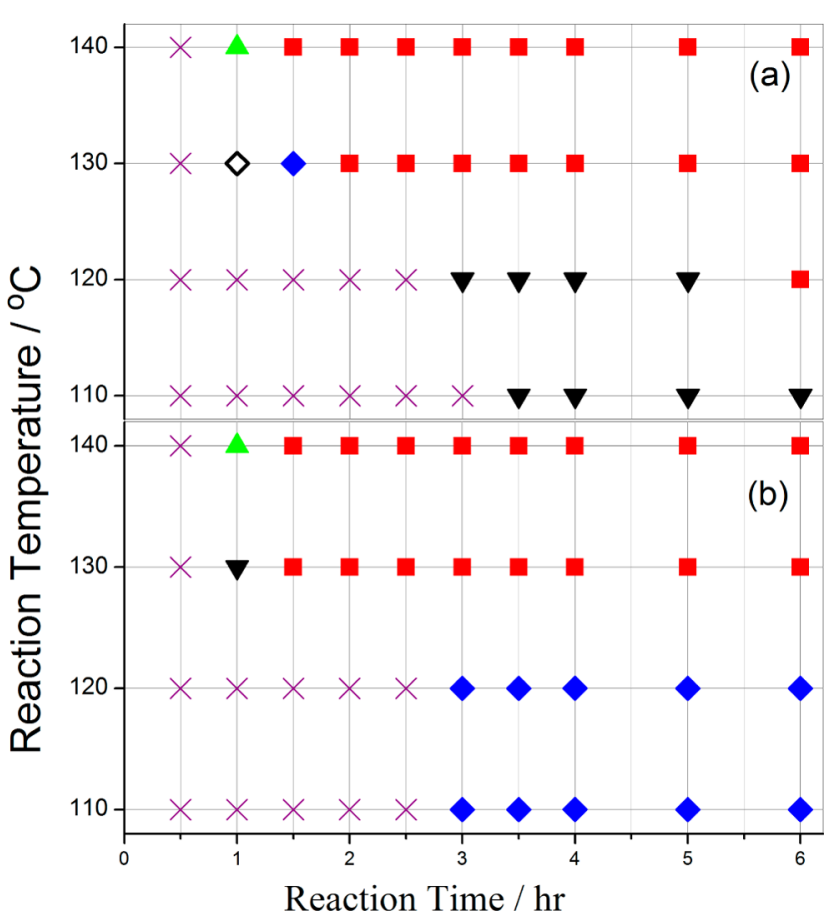

Figure 5. Synthesis parameter space for (a) unstirred and (b) stirred conditions. No solid mass as visible to the naked eye $(\times)$, intermediate phase $(\diamond)$, MOF-69c(desolv) with other intermediate phases (blue $\checkmark)$, MOF-5 + MOF-69c(desolv) and other intermediates ( $)$ ), MOF$5+$ MOF-69c(desolv) (green $\boldsymbol{\Delta})$, pure MOF-5 (red $\mathbf{\square})$.

synthesis mechanisms, clearly showing at least one intermediate phase present before the MOF-5 appearance for every temperature analyzed; often these intermediate phases include MOF-69c(desolv). This mapping also delineates the conditions best-suited for MOF-5 production. Where no solids were visible to the naked eye, the solution was deemed to have not yet produced any solid mass.

Analysis of solids present within samples over multiple time periods allowed evolution of solids present in the process of MOF-5 formation to be monitored. Performing multiple, identical runs allowed synthesis progress to be followed ex situ as a function of time without disturbing reaction mixtures, as required by removal of aliquots. This procedure has the additional advantage of providing an estimate of the quantity of solid formed for each time and temperature combination. At all temperatures, we found that no solid material is produced in the first 30 min of heating, as shown in Figure 5. Subsequent to this, all reaction mixtures show the appearance of various intermediate phases, often in a mixture with MOF-5. Longer reaction times, at $130{ }^{\circ} \mathrm{C}$ or above, show the elimination of intermediate phases and formation of MOF-5 as a single crystalline phase product. We found lower reaction temperatures required longer initiation times before formation of the first solids and mixtures of two or more solid phases persisting for longer times, extending up to at least $6 \mathrm{~h}$ at $110{ }^{\circ} \mathrm{C}$. When including all times and temperatures analyzed in this study, the number of solid crystalline materials increased to five, from the two seen at $140{ }^{\circ} \mathrm{C}$ under stirred conditions.

Effect of Stirring. Stirring has a significant effect on reaction progress, especially at temperatures below $130{ }^{\circ} \mathrm{C}$. Both stirred and unstirred reactions proceed for a period of 2.5-3 h, during which no solids are formed. After this initiation period, solids appear in both cases; however, stirring the reaction mixture leads to only intermediate phases formation, while the unstirred reaction shows a mixture of MOF-5, MOF$69 \mathrm{c}$ (desolv), and other intermediate phases, suggesting that agitation of the reaction mixture stabilizes these intermediates or otherwise hinders production of MOF-5. This could be due to compositional heterogeneities in unstirred systems where formation of MOF-5 might be favored in domains with reactant concentrations different from those of the bulk.

MOF-5 Formation Pathways. The reaction scheme and phase transitions observed in both stirred and unstirred solutions are shown below (Figure 6).

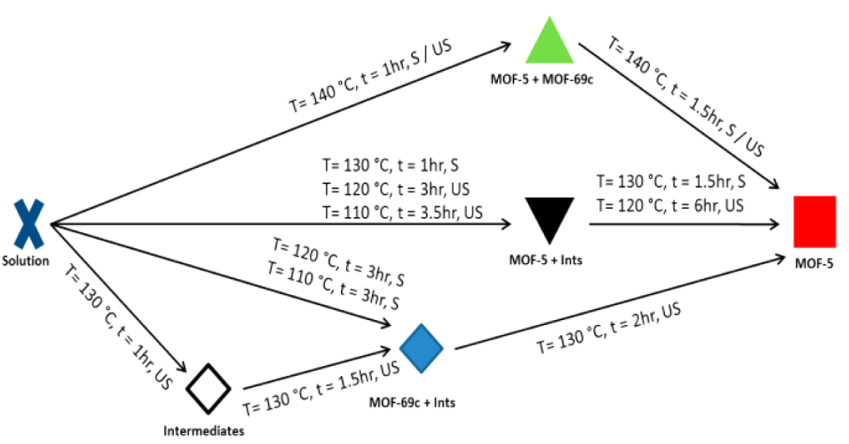

Figure 6. MOF-5 formation pathways. No solid mass as visible to the naked eye $(\times)$, intermediate phase $(\diamond)$, MOF-69c(desolv) with other intermediate phases (blue $\bullet$ ), MOF-5 + MOF-69c(desolv) and other intermediates (black $\boldsymbol{\nabla})$, MOF-5 + MOF-69c(desolv) (green $\boldsymbol{\Delta})$, pure MOF-5 (red $\mathbf{\square})$. Key (Temperature, Time phase transition occurs, $S=$ stirred, US = unstirred, S/US = occurs both in unstirred and stirred reactions).

Under all conditions investigated in this study, using either single or two-step synthetic processes, there was at least one intermediate phase observed prior to formation of pure MOF5 , which agrees with Ostwald's rule of stages, whereby the system passes through metastable intermediate(s) with stability nearest to the original state before reaching the most stable phase. $^{23,24}$ This implies that, when using in situ techniques ${ }^{18}$ to monitor solid formation during MOF-5 synthesis, one needs to take into account the presence of intermediates and/or multiple solid forms, in order to provide a complete picture of the evolution of MOF-5, due to a variety of possible structures present during early synthesis stages. 
These results indicate that the MOF-5 formation mechanism is considerably more complex than hitherto assumed and suggests that formation and stabilization of this, and most likely other coordination polymers, occurs in an extensive landscape of intermediate metastable solid phases influenced by numerous process parameters, including composition, temperature, reaction time, and stirring conditions. Crucially, much less significant effects of stirring at increased temperatures allows stirring conditions to be utilized to increase heat and mass transfer, thus facilitating scale-up to achieve reproducible and efficient production of large quantities of MOF-5.

High Concentration Synthesis. The concentrations analyzed were $1 \%, 3 \%, 5 \%, 10 \%, 20 \%$, and $30 \%$ solids. All samples showed high quality MOF-5 (see Figure 7), with the

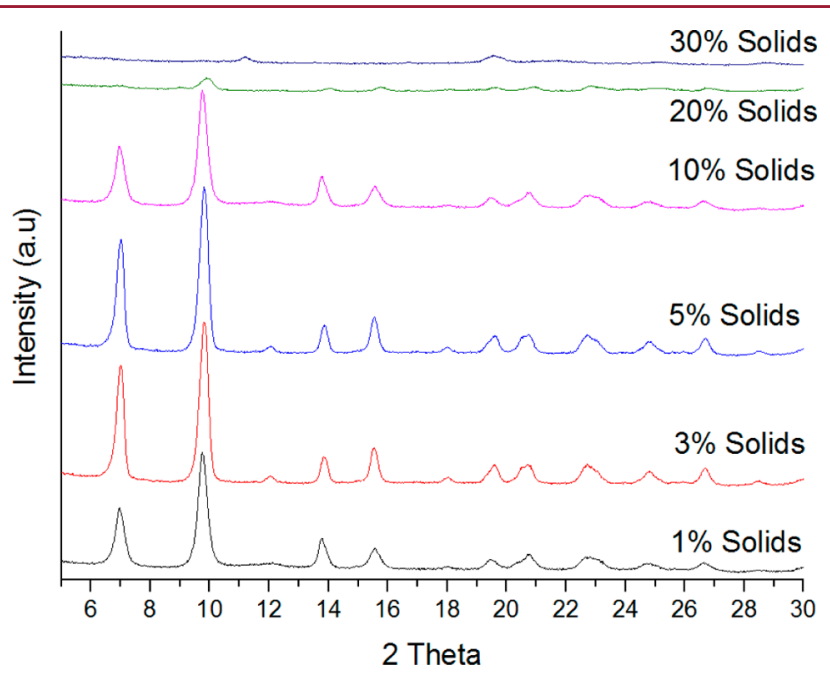

Figure 7. Final products obtained at $130{ }^{\circ} \mathrm{C}$ for $3 \mathrm{~h}$. $1 \%, 3 \%, 5 \%$, and $10 \%$ show MOF-5 in high quality; $20 \%$ solids show that MOF-5 is formed, but with low crystallinity and high amorphous content; 30\% solids show MOF-5 is not formed.

exceptions of $20 \%$ solids, which showed MOF-5 with poor crystallinity and broad, low intensity peaks ascribed to the presence of amorphous materials, and $30 \%$ solids, which did not produce MOF-5. Higher \% solids, up to $10 \%$, also had a positive effect on synthesis kinetics, resulting in formation of MOF-5 at shorter times relative to lower solids contents. Higher concentrations of precursors are more likely to form interpenetrated MOF structures, as supported by the observed reduction in Langmuir-specific surface area with the content of the solids showing an $80 \%$ reduction in SSA when moving from $1 \%$ to $10 \%$ solids.

Crystal structures were determined by XRD before and after TGA studies. For samples at 3, 5, and 10\% solid content, amorphous species were found to be present at very low levels, by calculation based on decomposition of samples, via heating to $\mathrm{ZnO}$, and high degrees of crystallinity coupled with an absence of broad peaks in the XRD patterns obtained. At 20\% solids, high loading of crystals formed prevents efficient mixing, resulting in reduced crystallinity and high amorphous content. Increasing solid concentrations also increases the yield of crystals produced (see Figure 8), from $\sim 70 \%$ yield (after solvent extraction) at $1 \%$ solids to over $90 \%$ yield for $10 \%$ solids, over the same duration at the same temperature, $3 \mathrm{~h}$ and $130{ }^{\circ} \mathrm{C}$. This produced $0.007 \mathrm{~g}$ of MOF-5 per milliliter solvent at $1 \%$ solids and increased by a factor greater than 10 to $0.09 \mathrm{~g}$

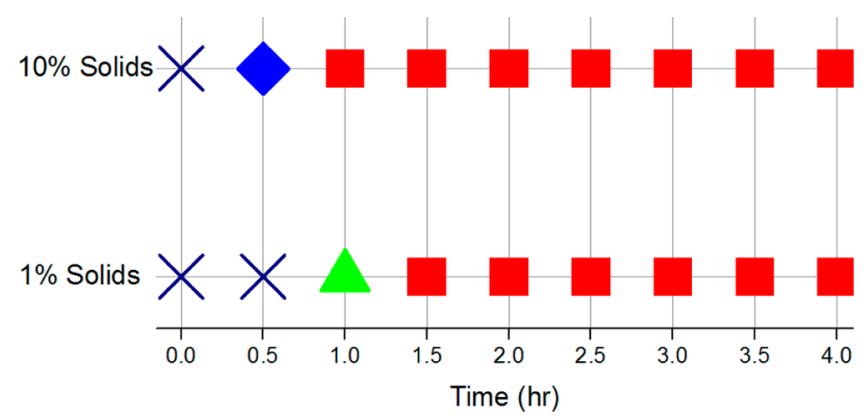

Figure 8. Evolution of crystalline solids with $10 \%$ solids, and $1 \%$ solids, heated at $140{ }^{\circ} \mathrm{C}$. MOF-69c(desolv) (blue $\left.\diamond\right)$, MOF-5 + MOF$69 \mathrm{c}$ (desolv) (green $\boldsymbol{\Delta}$ ), and MOF-5 (red $\boldsymbol{\square})$. Increased concentration reduced both the time for first solid formation and the time to produce MOF-5 at $140{ }^{\circ} \mathrm{C}$.

per milliliter of solvent at $10 \%$ solids. This decreases the solvent used per unit mass of MOF-5 synthesized by 10 times.

\section{CONCLUSIONS}

In conclusion, synthesis of MOF-5 under the conditions investigated here was shown to invariably involve initial formation of metastable intermediate solid phases. These phases transform into MOF-5 subject continued treatment, as shown by XRD and FTIR characterization of evolved solids. At $140{ }^{\circ} \mathrm{C}$, under stirring conditions, a single intermediate phase, isostructural with MOF-69c(desolv), forms initially before transforming into pure MOF-5 at relatively short times (up to $1.5 \mathrm{~h}$ ). It is notable that MOF-5 formation process showed significant changes below $130{ }^{\circ} \mathrm{C}$. At $130{ }^{\circ} \mathrm{C}$ and above, stirring had little effect relative to unstirred processes; however, at 120 ${ }^{\circ} \mathrm{C}$ and below, MOF-5 formation was adversely affected by stirring, with metastable intermediate phases persisting for many hours and an absence of MOF-5, which only appears at much longer times.

Varying further synthetic parameters, such as solid concentrations and the metal:ligand ratio, has shown that MOF-5 can be formed at a much higher concentration than previously reported, reducing solvent use by 10 times per unit mass of MOF-5 and accelerating formation kinetics. Further process intensification can be achieved by use of stoichiometric quantities of precursor materials, suggesting MOF-5 production at or above $130{ }^{\circ} \mathrm{C}$ with manipulation of the parameters analyzed here, can present a clear advantage in terms of scaleup and continuous manufacturing opportunities.

\section{ASSOCIATED CONTENT}

\section{S Supporting Information}

In-depth experimental procedure for single- and two-step processes, thermal stability graph, and yield analysis. This material is available free of charge via the Internet at http:// pubs.acs.org.

\section{AUTHOR INFORMATION}

\section{Corresponding Author}

*E-mail: ashleigh.fletcher@strath.ac.uk.

Notes

The authors declare no competing financial interest. 


\section{ACKNOWLEDGMENTS}

We thank the financial support provided by the EPSRC-DTG, the Department of Chemical and Process Engineering, and the Department of Pure and Applied Chemistry.

\section{REFERENCES}

(1) Tomic, E. A. J. Appl. Polym. Sci. 1965, 9, 3745-3752.

(2) Farha, O. K.; Hupp, J. T. Acc. Chem. Res. 2010, 43, 1166-1175.

(3) Czaja, A. U.; Trukhan, N.; Muller, U. Chem. Soc. Rev. 2009, 38, 1284-1293.

(4) Wang, Z. Q.; Cohen, S. M. Chem. Soc. Rev. 2009, 38, 1315-1329.

(5) Li, H.; Eddaoudi, M.; O’Keeffe, M.; Yaghi, O. M. Nature 1999, 402, 276-279.

(6) Yoo, Y.; Lai, Z. P.; Jeong, H. K. Microporous Mesoporous Mater. 2009, 123, 100-106.

(7) Sabouni, R; Kazemian, H.; Rohani, S. Chem. Eng. J. 2010, 165, 966-973.

(8) Ma, M.; Zacher, D.; Zhang, X. N.; Fischer, R. A.; Metzler-Nolte, N. Cryst. Growth Des. 2011, 11, 185-189.

(9) Liu, Y. Y.; Ng, Z. F.; Khan, E. A.; Jeong, H. K.; Ching, C. B.; Lai, Z. P. Microporous Mesoporous Mater. 2009, 118, 296-301.

(10) Li, J. P.; Cheng, S. J.; Zhao, Q.; Long, P. P.; Dong, J. X. Int. J. Hydrogen Energy 2009, 34, 1377-1382.

(11) Biemmi, E.; Christian, S.; Stock, N.; Bein, T. Microporous Mesoporous Mater. 2009, 117, 111-117.

(12) A. D. C. Burrows, K.; Friend, R. M. W; Mahon, M. F.; Rigby, S. P.; Warren, J. E CrystEngComm 2005, 7, 548-550.

(13) Chen, B.; Wang, X. J.; Zhang, Q. F.; Xi, X. Y.; Cai, J. J.; Qi, H.; Shi, S.; Wang, J.; Yuan, D.; Fang, M. J. Mater. Chem. 2010, 20, 37583767.

(14) Saha, D. P.; Wei, Z. J.; Deng, S. G. Sep. Purif. Technol. 2009, 64, 280-287.

(15) Calleja, G.; Botas, J. A.; Orcajo, M. G.; Sanchez-Sanchez, M. J. Porous Mater. 2010, 17, 91-97.

(16) Saha, D.; Deng, S. J. Colloid Interface Sci. 2010, 348, 615-620. (17) Zhao, Z. X.; Li, Z.; Lin, Y. S. Ind. Eng. Chem. Res. 2009, 48, 10015-10020.

(18) Hermes, S.; Witte, T.; Hikov, T.; Zacher, D.; Bahnmuller, S.; Langstein, G.; Huber, K.; Fischer, R. A. J. Am. Chem. Soc. 2007, 129, 5324-5325.

(19) Rosi, N. L.; Kim, J.; Eddoudi, M.; Chen, B.; O’Keeffe, M.; Yaghi, O. M. J. Am. Chem. Soc. 2005, 127, 1504-1518.

(20) S. W. Hausdorf, J.; Mossig, R.; Mertens, O. R. L. J. Phys. Chem. A 2008, 112, 7567-7576.

(21) Kaye, S. S.; Dailly, A.; Yaghi, O. M.; Long, J. R. J. Am. Chem. Soc. 2007, 129, 14176-14177.

(22) (a) Saha, D. P. D.; Deng, S. G.; Yang, Z. G. J. Porous Mater. 2009, 16, 141-149. (b) Saha, D.; Deng, S. G. Int. J. Hydrogen Energy 2009, 34, 2670-2678.

(23) Threlfall, T. Org. Process Res. Dev. 2003, 7, 1017-1027.

(24) Chung, S. Y.; Kim, Y. M.; Kim, J. G.; Kim, Y. J. Nat. Phys. 2009 $5,68-73$. 